Portland State University

PDXScholar

\title{
Changing Attitudes Toward Sustainable Transportation: The Impact of Meta-Arguments on Persuasion
}

David M. Sanbonmatsu

University of Utah

David L. Strayer

University of Utah

Follow this and additional works at: https://pdxscholar.library.pdx.edu/trec_reports

Part of the Community Psychology Commons, Experimental Analysis of Behavior Commons, and the Transportation Commons

Let us know how access to this document benefits you.

\section{Recommended Citation}

Sanbonmatsu, David M., and David L. Strayer. Changing Attitudes Toward Sustainable Transportation: The Impact of Meta-Arguments on Persuasion. NITC-RR-801. Portland, OR: Transportation Research and Education Center (TREC), 2017. https://doi.org/10.15760/trec.180

This Report is brought to you for free and open access. It has been accepted for inclusion in TREC Final Reports by an authorized administrator of PDXScholar. Please contact us if we can make this document more accessible: pdxscholar@pdx.edu. 


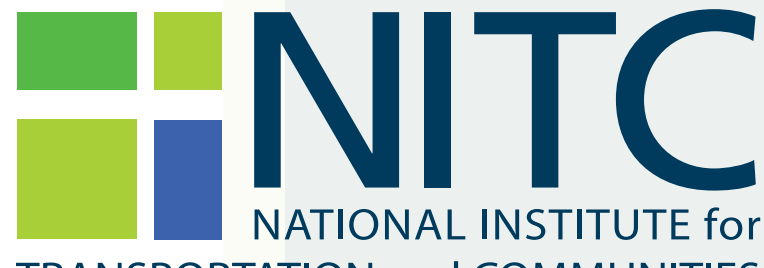

TRANSPORTATION and COMMUNITIES

FINAL REPORT

Changing attitudes toward sustainable transportation: The impact of meta-arguments on persuasion

NITC-RR-801 — August 2017

NITC is a U.S. Department of Transportation

national university transportation center.

HI!" TREC 



\section{CHANGING ATTITUDES TOWARD SUSTAINABLE TRANSPORTATION: \\ THE IMPACT OF META-ARGUMENTS ON PERSUASION}

\section{Final Report}

\section{NITC-RR-801}

by

David M. Sanbonmatsu \& David L. Strayer

University of Utah

for

National Institute for Transportation and Communities (NITC)

P.O. Box 751

Portland, OR 97207
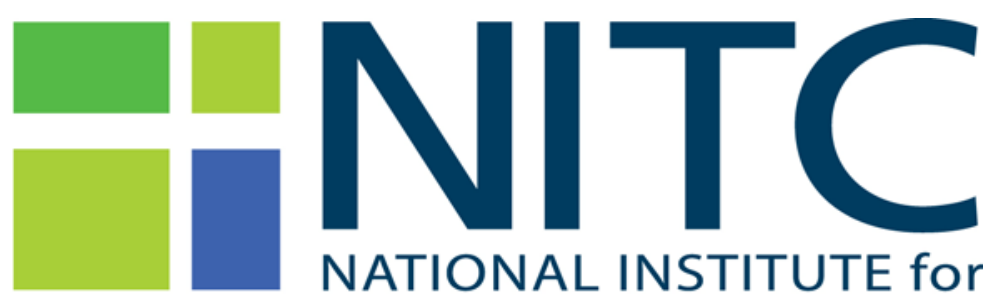

TRANSPORTATION and COMMUNITIES

August 2017 


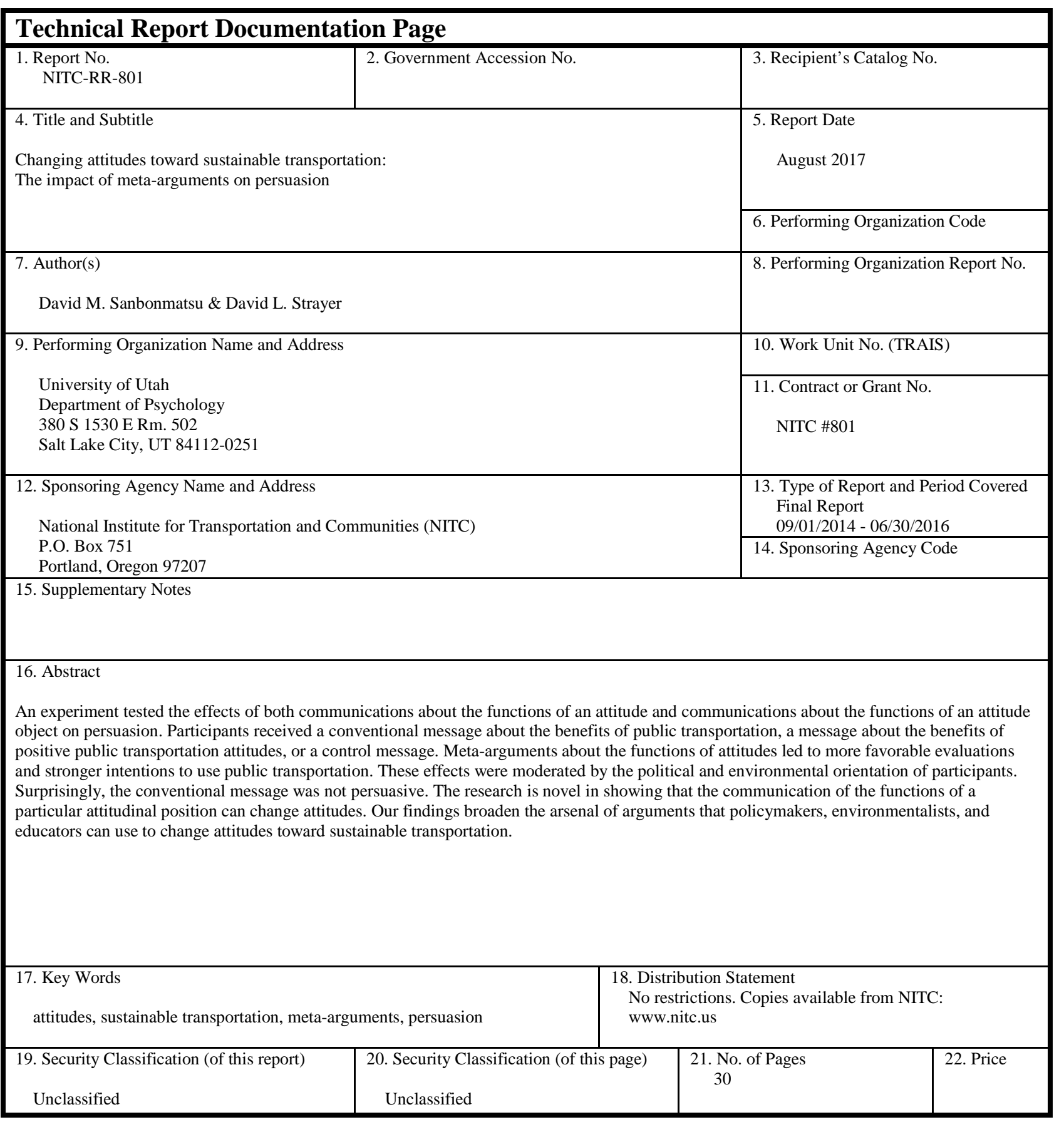





\section{ACKNOWLEDGEMENTS}

This project was funded by the National Institute for Transportation and Communities (NITC). We greatly appreciate NITC's support of our investigation of the effects of communications on attitudes toward sustainable transportation. We are also appreciative of the patience that was shown us by the NITC staff during our difficulties with the project.

\section{DISCLAIMER}

The contents of this report reflect the views of the authors, who are solely responsible for the facts and the accuracy of the material and information presented herein. This document is disseminated under the sponsorship of the U.S. Department of Transportation University Transportation Centers Program and the AAA Foundation for Traffic Safety in the interest of information exchange. The U.S. Government and the AAA Foundation for Traffic Safety assume no liability for the contents or use thereof. The contents do not necessarily reflect the official views of the U.S. Government and the AAA Foundation for Traffic Safety. This report does not constitute a standard, specification, or regulation.

\section{RECOMMENDED CITATION}

Sanbonmatsu, David M., and David L. Strayer. Changing attitudes toward sustainable transportation: The impact of meta-arguments on persuasion. NITC-RR-801. Portland, OR: Transportation Research and Education Center (TREC), 2017. 



\section{TABLE OF CONTENTS}

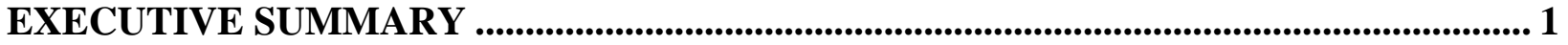

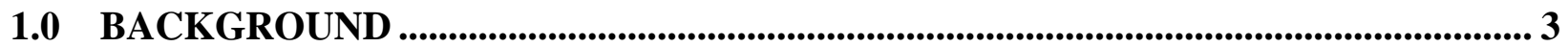

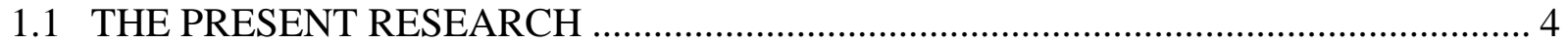

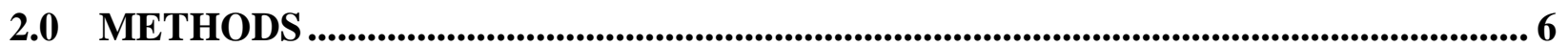

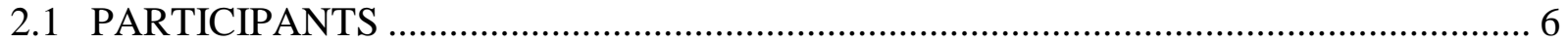

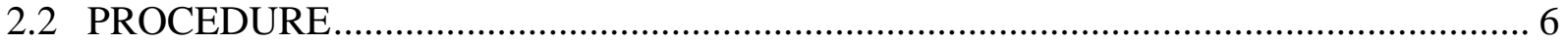

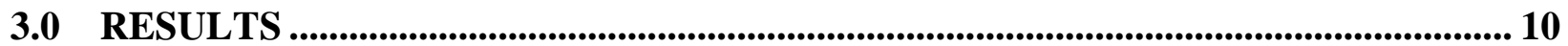

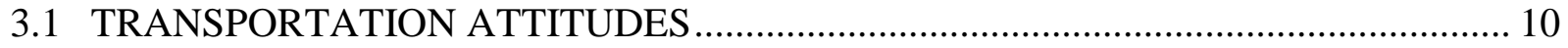

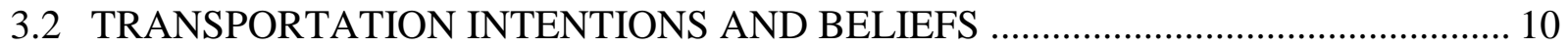

3.3 THE IMPACT OF POLITICAL ORIENTATION ON PERSUASION ......................... 11

3.4 THE IMPACT OF ENVIRONMENTAL ORIENTATION ON PERSUASION ............. 15

4.0 DISCUSSION AND CONCLUSIONS ................................................................... 19

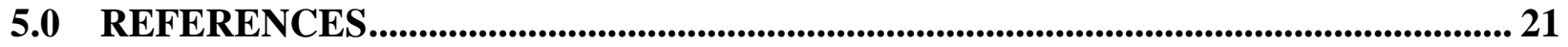

\section{LIST OF TABLES}

Table 3.1: Attitudes toward public transportation and driving as a function of message............ 10

Table 3.2: Intentions toward and beliefs about public transportation and driving as a function of message

\section{LIST OF FIGURES}

Figure 3.1: Attitudes toward public transportation and driving as a function of political orientation and message

Figure 3.2: Attitude toward driving to work or school as a function of political orientation and message

Figure 3.3: Intention to increase use of public transportation as a function of political orientation and message

Figure 3.4: Attitude toward public transportation as a function of environmental orientation and message Error! Bookmark not defined.

Figure 3.4: Attitude toward public transportation as a function of environmental orientation and message 16

Figure 3.5: Intention to increase use of public transportation as a function of environmental attitudes and message. 



\section{EXECUTIVE SUMMARY}

A major contributor to global climate change is the heavy reliance on cars for transportation and the limited use of public transit. One of the most central determinants of bus ridership and other environmental behaviors such as recycling and waste composting are attitudes (Heath \& Gifford, 2002; Wan, Shen, \& Choi, 2017). Research examining the attitudes underlying transportation decisions has shown that many people resist using public transit because they perceive it to be unreliable, inconvenient, lower-status, and unsafe (e.g. Karash et al., 2008; Rhindress et al., 2008). Thus, a challenge facing policymakers and environmentalists seeking to decrease driving and increase the use of public transportation is to change these negative attitudes.

One of the most fundamental mechanisms for changing attitudes and, hence, behavior is persuasion. In our NITC-funded research, we investigated the effectiveness of different persuasive messages in changing transportation attitudes. Public service messages typically convey the merits of public transportation and the costs of driving (e.g., "Using public transportation causes significantly less air pollution than driving a car," "families that use public transportation can reduce their household expenses by over \$6,000 annually”). Our study examined the persuasiveness of meta-arguments about the functional value of adopting more favorable attitudes toward public transportation options. These are messages that convey the positive benefits, opportunities, and images associated with a particular attitude or position (e.g., "Surveys indicate that corporate America is increasingly hiring employees with a strong orientation toward environmentally sustainable practices such as public transportation”, "favorable views of public transit, bicycling, and walking have become associated with better health and a strong community orientation.”). Participants in an experiment read a message conveying either conventional arguments for using public transportation or meta-arguments for holding more favorable attitudes. Participants in a control condition read a message about the virtues of recycling. Afterwards, they indicated their attitudes toward public transportation and toward driving to work or school. They also conveyed their intentions to drive or utilize public transit in the future.

The presentation of meta-arguments tended to contribute to more favorable evaluations of public transportation and stronger intentions to use public transit in the future. This suggests that communicating the benefits of more positive attitudes toward buses and railways, and the costs of favorable attitudes toward driving, may be an alternative and effective approach for changing transportation behavior. The finding also contributes to theory on attitude change by demonstrating the impact on persuasion of meta-arguments about the functional value of adopting new attitudes. Surprisingly, the conventional message had little impact on evaluations of public transportation and intentions to use public transit; we speculate that most college undergraduates are familiar with the conventional arguments that were presented and may be little persuaded by hearing what they have already learned. Politically conservative participants and participants who are indifferent about the environment are particularly likely to have been persuaded by meta-arguments rather than conventional arguments. In contrast, liberal and pro- 
environment participants were not influenced more by the meta-arguments message than the conventional message. This finding indicates that the relative efficacy of conventional and metaarguments for sustainable transportation may be dependent on the message recipient. Educators and policymakers may need to tailor their arguments for their audiences to maximize the impact of their communications.

Our research and findings are in line with the U.S. DOT strategic plan to transform our transportation system into one that burns less oil and emits less carbon. The study investigated communications that can help to persuade people to drive less, and walk, bicycle, and use mass transit more. In addition, the study explored which persuasive arguments are likely to be most effective with different user groups or segments. As such, the research helps to provide a new set of arguments or tools for educational programs and communications aimed at changing people's transportation attitudes and behavior. Thus, the research was in keeping with the U.S. DOT goal to make our communities more livable by increasing the sustainability of transportation behavior. 


\subsection{BACKGROUND}

A major contributor to global climate change is the heavy reliance on cars for transportation and the limited utilization of public transit. One of the most central determinants of bus ridership and other environmental behaviors such as recycling and waste composting are attitudes (Heath \& Gifford, 2002; Wan, Shen, \& Choi, 2017). Research examining the attitudes underlying transportation decisions has shown that many people resist using public transit because they perceive it to be unreliable, low-status, inconvenient, and sometimes unsafe (e.g. Karash et al., 2008; Rhindress et al., 2008). In contrast, personal automobile use is often regarded as highly beneficial, even among those who are aware of the environmental costs (Steg and Sievers, 2000). Thus, a challenge facing policymakers and environmentalists seeking to decrease driving and increase the use of public transportation is to change these attitudes.

One of the most fundamental mechanisms for changing attitudes and, hence, behavior is persuasion (Petty \& Cacioppo, 1981). Prior research has shown that persuasive messages can be highly effective in changing environmental attitudes and intentions (Seyranian, Sinatra, \& Polikoff, 2015). Generally, communications present arguments pertaining to the attitude object the person, issue, action, event, or target that is the topic of the communication. However, the present research took the novel approach of investigating the efficacy of messages aimed at changing people's thinking or meta-cognitions about their attitudes. Specifically, the study investigated the impact of meta-arguments for changing attitudes toward sustainable transportation.

People harbor beliefs about and evaluations of attitude objects. They also have meta-cognitions about their beliefs and evaluations that play an important role in attitude formation and change (Katz, 1960; Maio \& Olsen, 2000). In thinking about transportation, individuals not only have beliefs about and attitudes toward driving, bicycling, walking, and taking the bus (e.g., "Driving contributes to air pollution"), they also have cognitions about the costs and benefits of attitudes toward these transportation options (e.g., "A positive view of public transit makes me look like a progressive and community-oriented person”). Thus, attitudes are not based solely on assessments of the attitude object; people's meta-cognitions about what particular stances do or could do for them also shape the attitudes they adopt. In some instances, attitudes form because they aid in social adjustment; that is, they help individuals get along with others. In other instances, attitudes form because they are consistent with a desired identity or because it is believed they will be instrumental in achieving more tangible goals.

Generally in persuasion, arguments are presented that pertain to the attitude object or attitudinal issue. Marketing messages about mass transit typically convey that driving creates pollution and is expensive, and that public transportation is a reliable and healthy alternative (Karash et al., 2008). Our analysis suggests that persuasion may also take place through the communication of strong meta-arguments about the functional value of holding a particular attitude. We believe that in communications about public transportation, meta-arguments can be presented that many people will find persuasive. Recent surveys and interviews indicate there is strong and growing support for public transit, walking, and bicycling, particularly among younger adults, and that it is becoming "cool” to have positive attitudes about sustainable forms of transportation (Davis, 
Dutzik, \& Baxandall, 2012). Research also suggests that businesses are increasingly seeking employees with a strong orientation toward sustainability (Deloitte LLP, 2010). Thus, arguments can be made that positive attitudes toward sustainable transportation may help individuals to fit in with their peers, increase their viability in the job market, and foster a more positive identity and social image. This analysis suggests that the range of communications that are effective in changing public transit attitudes may be broader than has been previously assumed.

\subsection{THE PRESENT RESEARCH}

Our NITC sponsored research focused on improving the livability of our communities by examining new ways of changing attitudes toward environmentally sustainable transportation. The study attempted to show that meta-concerns are an important determinant of attitudes toward different transportation options. More importantly, the research examined the efficacy of different persuasive approaches for improving attitudes toward public transit and, hence, increasing the utilization of more sustainable alternatives. Finally, the research investigated whether the relative impact of conventional vs. meta-cognitive persuasive arguments varies as a function of different user groups. It was hoped that the findings of the research would broaden the range of communications that are effective in changing transportation attitudes and aid in the development of educational programs aimed at improving transportation behavior.

A study was conducted to examine the efficacy of meta-cognitive communications about the functional value of more positive attitudes toward sustainable transportation. The study used an experimental design in a controlled environment to provide compelling evidence of the causal impact of meta-arguments on transportation attitudes and intentions.

Participants in the experiment received one of three persuasive messages. Participants in the conventional argument condition received the typical arguments for using public transportation. Meta-argument condition participants received information about the benefits of adopting more positive attitudes toward public transportation. Finally, control participants received a communication about the merits of recycling. The control article promoted environmental causes but did not focus on sustainable transportation. Thus, it was designed to help discern whether the effects of the conventional and meta-argument messages were the result of the presentation of specific arguments for sustainable transportation or the result of the general activation of proenvironment thinking. We anticipated that both the conventional argument and the metaargument communications would lead to more favorable attitudes toward public transportation than the control article.

One of the important lessons of the persuasion literature is that the efficacy of different communications is often dependent on important characteristics of the message recipient. A secondary goal of the study was to demonstrate that the relative effectiveness of conventional and meta-cognitive persuasive approaches might be dependent on the segment of the market being targeted. Many conventional arguments for taking public transportation rather than driving may not be persuasive for people who are indifferent about the environment. For example, a person who is unconcerned with environmental issues is not likely to be influenced by arguments about the impact of driving on air quality. However, these individuals may be more readily 
persuaded by meta-arguments about the benefits of holding more-favorable attitudes toward sustainable transportation (e.g., "individuals with positive attitudes toward public transit, bicycling, and walking are often perceived to be healthy, community-oriented, and progressive"). Similarly, individuals who are politically conservative may be less concerned about the environment and less interested in saving money by riding mass transit, and, hence, may be less influenced by conventional arguments. Thus, the study examined whether the effects of conventional arguments and meta-arguments on transportation attitudes are moderated by political and environmental orientation. 


\subsection{METHODS}

\subsection{PARTICIPANTS}

Moderate to large message effects (effect sizes of 0.50 to 0.70 ) were expected based on prior research in the persuasion literature. A power analysis adopting an alpha of 0.05 (2-tailed) and power of $80 \%$ indicated that a sample of at least 135 participants was needed to demonstrate between-subjects differences in attitudes as a function of the messages.

One hundred forty-one male and female undergraduates participated in the study for extra course credit in psychology courses at the University of Utah. Participants were randomly assigned to one of three message conditions: 46 received the meta-arguments message, 49 the conventional message, and 46 the recycling control message.

\subsection{PROCEDURE}

Participants were seated at a computer station in a lab room for a study of "social communications.” They were informed that after a series of measures about their background and opinions, they would "receive information about different social topics such as gun control and the environment." They were told, "You will be asked to convey your opinions about the communications and your views about the social issues."

Participants began by completing the "Social Opinion Survey." After indicating their gender and age, they were asked, "What is your political affiliation?" Participants responded with one of four options: Democrat, Republican, Independent, or Other. They subsequently answered the question, “To what extent are you politically conservative or liberal?” on a 5-point scale anchored by I am highly conservative and I am highly liberal, and containing the middle response I am neither conservative nor liberal.

After answering four filler questions about national security, they were asked to indicate their level of agreement with the following five statements about the environment and their attitudes:

1. Global warming is a very serious problem.

2. The environment is a low priority for me compared with a lot of other things in my life.

3. I am environmentally friendly in most things that I do.

4. I worry about the effects of environmental pollution on my family's health

5. The so-called “ecological crisis” facing humankind has been greatly exaggerated. 
Participants conveyed their beliefs and attitudes on a five-point scale anchored by strongly agree and strongly disagree. Their agreement with these statements was averaged after reverse-coding the responses to the two environment-unfriendly items (Nos. 2 and 5) to create an overall index of environmental orientation. They finished the Social Opinion Survey by answering five filler questions on immigration.

In the next phase of the study, participants read excerpts from articles on social issues and then conveyed their attitudes toward the topic. They first read and answered questions about an article on gun control. This was followed by one of three experiment-relevant communications. In the conventional and meta-arguments conditions, the communication began with the following background information:

Recently, the Center for Business and the Environment at Stanford University wrote an online article entitled, "Why everyone wins with public transportation" that was featured on the Center's website and reported by several news services. The article articulated many important environmental arguments for using buses, trams, and other forms of public transit. It also presented several less familiar but compelling reasons to favor more sustainable transportation. Here are excerpts from the article.

In the conventional message condition, the following highlights from the article were presented:

Riding a bus is 79 times safer than riding in an automobile, and riding a train or subway is even safer.

According to an American Public Transportation Association study, families that use public transportation can reduce their household expenses by over $\$ 6,000$ annually.

Using public transportation, walking, and bicycling significantly reduce the air pollution from driving a car.

Public transportation diminishes the use of valuable natural resources and our reliance on foreign oil. According to one environmental organization, if just one more American out of 10 used public transportation daily, U.S. reliance on foreign oil would decrease 40 percent.

Public transportation, walking, and bicycling reduce the congestion on our roadways and significantly lower commute times.

In the meta-arguments message condition, the following highlights were presented:

A 2012 business study indicates that corporate America is increasingly hiring employees with a positive orientation toward environmentally sustainable practices such as public transportation. 
The study showed that applicants who are supportive of practical environmental solutions such as improved public transit are perceived to be forward thinking and progressive by companies.

A recent PIRG study reports that positive attitudes toward various modes of public transit such as buses, trams, and trains are becoming more and more favored, particularly amongst 20 and 30 year olds.

Surveys suggest that individuals who are wedded to their automobiles and who view public transportation options such as riding the bus and light rail as second class are increasingly viewed as dinosaurs who are out of touch with today's realities.

A recent survey indicates that favorable views of public transit, bicycling, and walking have become associated with better health and a strong community orientation.

In the recycling control condition, participants read excerpts from an online article, purportedly by the Center for Business and the Environment at Stanford University, titled "Why everyone wins with recycling.” This alleged article presented strong arguments for recycling such as "Recycling is good for the environment. Recycling requires far less energy, uses fewer natural resources, and keeps waste from piling up in landfills."

The background information and article excerpts were presented for 90 seconds. Afterwards, participants in the conventional argument and meta-argument conditions were asked, "To what extent was the information presented in the article on sustainable transportation familiar to you? That is, to what extent have you heard the arguments before?” They indicated their familiarity on a five-point scale anchored by not at all familiar and highly familiar. In the recycling control condition, participants answered 6 questions about the article and their attitudes toward recycling. Participants in all 3 message conditions then proceeded to answer a series of questions about transportation. They first indicated their evaluation of "public transportation (e.g., buses, light rail)" and their evaluation of "driving an automobile to work or school" on seven-point scales anchored by very negative and very positive. Participants then conveyed their agreement with the following statements on a five-point scale anchored by strongly agree and strongly disagree:

I believe that communities and the government should make public transportation (e.g., buses, light rail) a major priority.

I intend to increase my usage of public transportation (e.g., buses, light rail) in the future.

I intend to diminish my reliance on cars to get places in the future 
Two individual difference measures were administered for exploratory purposes following the measurement of transportation intentions and beliefs. Afterwards, participants were debriefed, thanked, and credited for their participation. 


\subsection{RESULTS}

\subsection{TRANSPORTATION ATTITUDES}

The first set of analyses examined the effects of the messages on transportation attitudes (see Table 2.1). A one-way Analysis of Variance (ANOVA) revealed that attitudes toward public transportation varied as a function of the message, $F(2,138)=3.23, p=0.042, \eta^{2}=0.045$. A planned comparison revealed that evaluations of public transportation were more favorable in the meta-arguments condition than in the recycling control condition, $t(138)=2.52, p=0.013, d=$ 0.53 . Public transportation attitudes did not differ between the recycling control and conventional arguments conditions, $t(138)=1.53, p=0.128, d=0.32$.

An ANOVA revealed that participants' attitudes toward driving to work or school differed marginally as a function of the message, $F(2,138)=2.77, p=0.066, \eta^{2}=0.084$. Planned contrasts indicate that relative to the recycling control condition, evaluations of driving were less favorable after meta-arguments were presented, $t(138)=2.14, p=0.034, d=0.34$; they also tended to be less favorable after conventional arguments were presented, $t(138)=1.69, p=$ $0.093, d=0.26$.

Table 3.1: Attitudes toward public transportation and driving as a function of message

\begin{tabular}{l|l|l|l}
\hline & Recycling Control & Conventional Arguments & Meta-arguments \\
\cline { 2 - 3 } $\begin{array}{l}\text { Evaluation of public } \\
\text { transportation }\end{array}$ & $1.87(0.96)$ & $2.18(1.19)$ & $2.39(0.77)$ \\
\hline $\begin{array}{l}\text { Evaluation of driving to } \\
\text { work or school }\end{array}$ & $1.11(1.37)$ & $0.65(1.36)$ & $0.48(1.24)$ \\
\hline
\end{tabular}

Notes. Seven-point scale anchored by $-3=$ Highly negative and $+3=$ Highly positive Standard deviations in parentheses

\subsection{TRANSPORTATION INTENTIONS AND BELIEFS}

The next set of analyses examined the effects of the messages on transportation intentions and beliefs (see Table 3.2). An ANOVA revealed that the effect of the messages on the belief that communities and the government should make public transportation a priority was not significant, $F(2,138)=1.22, p=0.30, \eta^{2}=0.017$. Planned comparisons indicate that prioritizing public transportation did not differ in the meta-argument and conventional argument conditions from the recycling control condition (meta-argument vs. recycling control: $t(138)=1.38, p=$ $0.17, d=0.38$; conventional vs. recycling control: $t(138)=1.35, p=0.18, d=0.36$ ).

An ANOVA revealed that the intention to increase personal use of public transportation was significantly affected by the message, $F(2,138)=5.09, p=0.007, \eta^{2}=0.069$. Participants conveyed much stronger intentions to use public transportation in the meta-arguments condition than in the recycling control condition, $t(138)=3.20, p=0.002, d=0.70$. Participants' 
intentions did not differ between the recycling control and conventional arguments conditions, $t(138)=1.60, p=0.111, d=0.35$.

Finally, an ANOVA indicated that the intention to reduce reliance on cars was not significantly affected by the type of message, $F<1$. Planned contrasts indicate that neither the comparison of meta-arguments vs. recycling control nor the comparison of conventional arguments vs. recycling control was significant, both $t<1.2$.

Table 3.2: Intentions toward and beliefs about public transportation and driving as a function of message

\begin{tabular}{l|l|l|l}
\hline & Recycling Control & Conventional Arguments & Meta-arguments \\
\hline $\begin{array}{l}\text { Communities should } \\
\text { prioritize public } \\
\text { transportation }\end{array}$ & $2.09(0.76)$ & $1.88(0.81)$ & $1.87(0.72)$ \\
\hline $\begin{array}{l}\text { Intend to increase usage of } \\
\text { public transportation }\end{array}$ & $2.78(0.96)$ & $2.47(1.04)$ & $2.15(0.82)$ \\
\hline $\begin{array}{l}\text { Intend to diminish reliance } \\
\text { on cars }\end{array}$ & $2.98(1.06)$ & $2.94(1.09)$ & $2.72(1.00)$ \\
\hline
\end{tabular}

Notes. Five-point scale anchored by $1=$ Strongly agree and $5=$ Strongly disagree

Standard deviations in parentheses

\subsection{THE IMPACT OF POLITICAL ORIENTATION ON PERSUASION}

Analyses were conducted to examine whether the effects of the communications on transportation attitudes and intentions depended on the political orientation of participants. Rather than using a median split or some other technique of dividing the participants based on numerical proportions, or assuming a continuum and using regression analyses, we opted to divide participants on the basis of their political self-categorizations. Participants were dichotomized as liberal (a response of 4 or 5 - somewhat liberal or highly liberal) or as relatively conservative (a response of 3 or lower - neither liberal or conservative, somewhat conservative, or highly conservative). There were 73 liberal and 68 relatively conservative participants in the sample.

Figure 3.1 presents the mean evaluations of public transportation as a function of political orientation and the presented message. A 2 × 3 between-subjects ANOVA revealed a main effect of political orientation, $F(1,135)=10.35, p=0.006, \eta p^{2}=0.071$. Not surprisingly, liberals $(M=$ $2.42, S D=0.76)$ evaluated public transportation more favorably than conservatives $(M=1.85$, $S D=1.15)$. The political orientation by message interaction was not significant, $F(2,135)=1.11$, $p=0.334, \eta p^{2}=0.016$. However, planned contrasts revealed that conservatives evaluated public transportation more favorably after meta-arguments were presented than after the recycling control message was presented, $t(135)=2.57, p=0.011, d=0.83$. Their evaluations in the conventional arguments condition did not differ from those in the recycling control condition, $t(135)=1.33, p=0.186, d=0.39$. Liberals' evaluations of public transportation did not differ after meta-arguments or conventional arguments, as opposed to the control message, were presented (both $t<1$ ). 


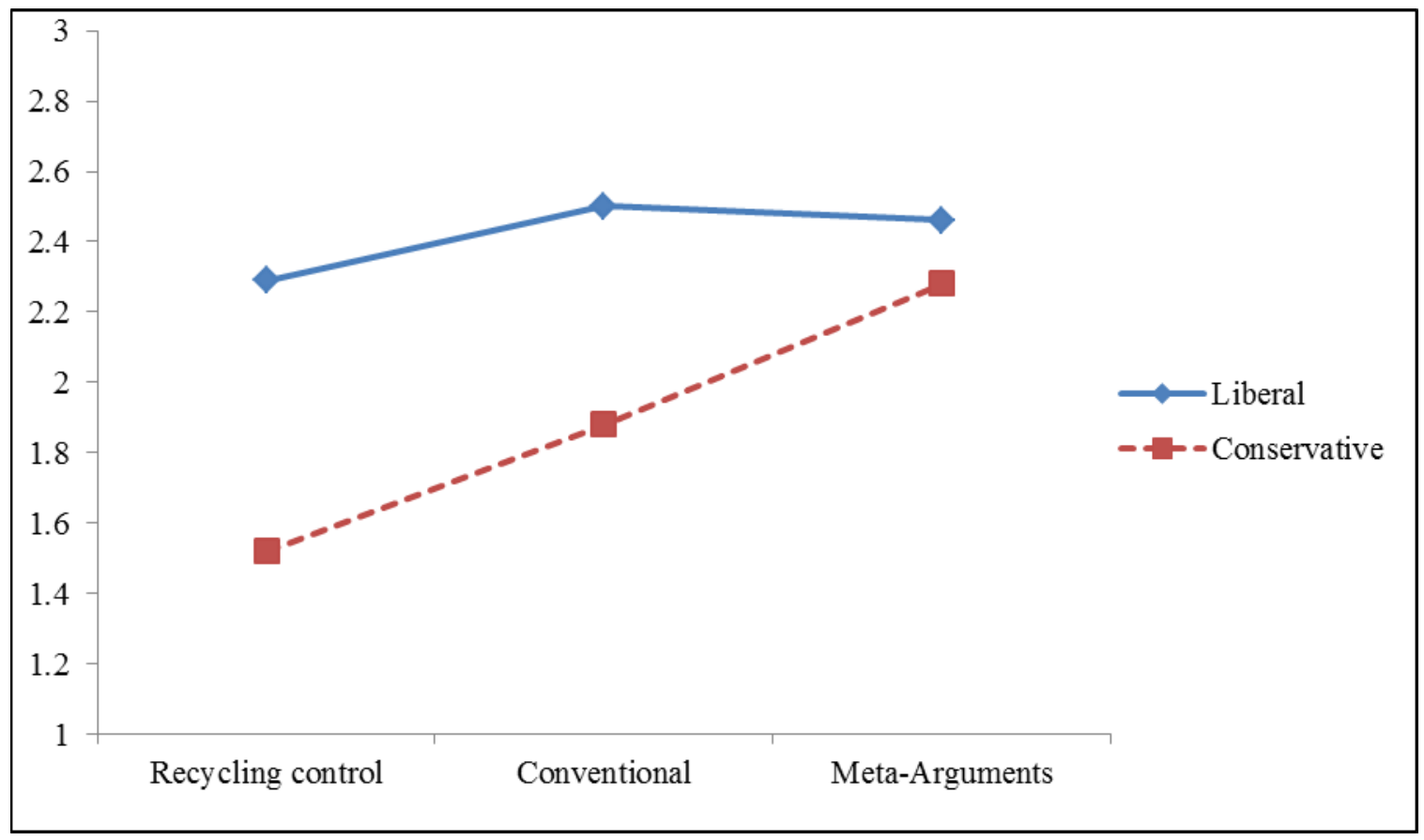

Figure 3.1: Attitudes toward public transportation and driving as a function of political orientation and message

Figure 3.2 presents the mean evaluations of driving to work or school as a function of political orientation and the presented message. An ANOVA of attitudes toward driving revealed a main effect of political orientation, $F(1,135)=4.66, p=0.041, \eta p^{2}=0.031$. Not surprisingly, liberals $(M=0.49, S D=1.28)$ evaluated driving less favorably than conservatives $(M=1.01, S D=1.37)$. The political orientation by message interaction was not significant, $F<1$. However, planned contrasts revealed that conservatives evaluated driving less favorably after meta-arguments were presented than after the recycling control message was presented, $t(135)=1.97, p=0.051, d=$ 0.46. Their evaluations did not differ between the recycling control and conventional arguments conditions, $t<1$. Liberals' evaluations of driving did not differ among the three message conditions (meta-argument vs. recycling control: $t=1.00$; conventional vs. recycling control: $t(135)=1.32, p=0.189, d=0.30)$. 


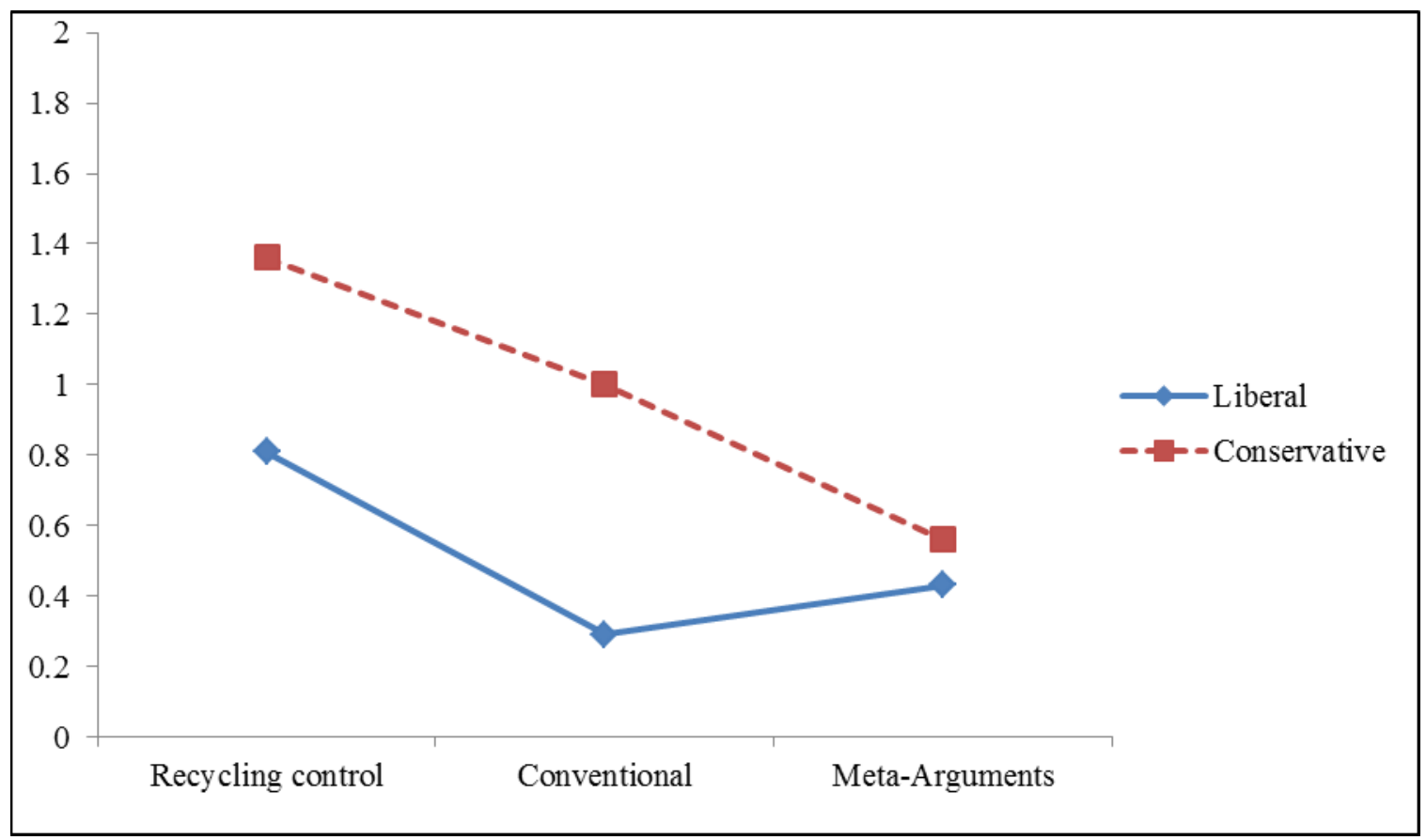

Figure 3.2: Attitude toward driving to work or school as a function of political orientation and message

Figure 3.3 presents the intention to increase use of public transportation as a function of political orientation and the presented message. An ANOVA revealed a main effect of political orientation, $\mathrm{F}(1,135)=4.56, \mathrm{p}=0.035, \eta \mathrm{p} 2=0.033$, as liberals $(\mathrm{M}=2.27, \mathrm{SD}=0.93)$ conveyed stronger intentions to use public transportation than conservatives $(\mathrm{M}=2.68$, $\mathrm{SD}=$ 0.98). The political orientation by message interaction was not significant, $F(2,135)=1.75, \mathrm{p}=$ $0.178, \eta p 2=0.025$. However, planned contrasts revealed that conservatives expressed stronger intentions to use public transportation after meta-arguments were presented as opposed to the recycling control message, $t(135)=3.38, p<0.001, d=1.12$. Their intentions did not differ between the recycling control and conventional arguments conditions, $t(135)=1.52, p=0.131, d$ $=0.46$. In contrast, the intentions of liberals to use public transportation did not differ among the three conditions (meta-argument vs. recycling control: $t<1$; conventional vs. recycling control: $t$ $<1)$. 


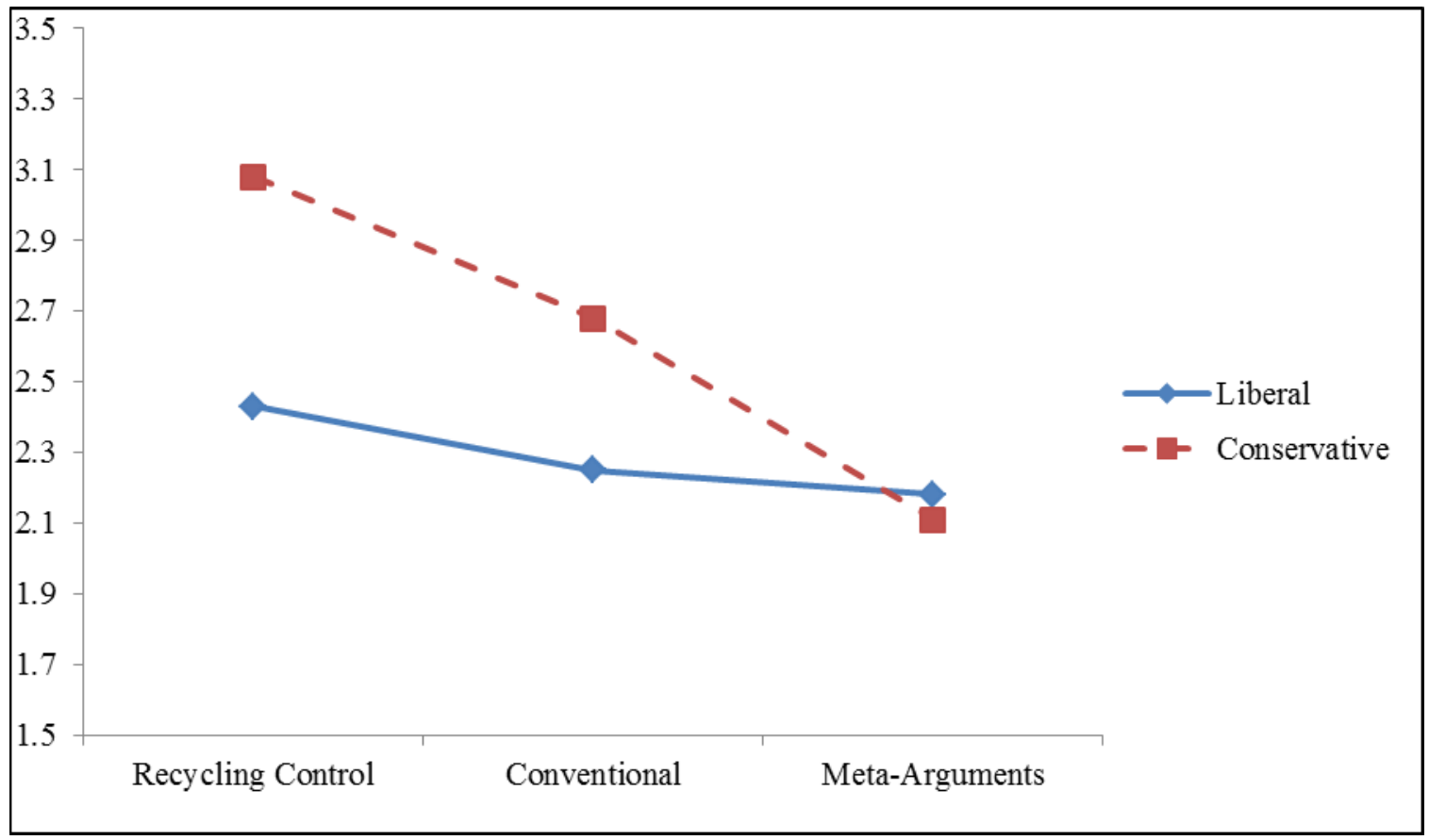

Figure 3.3: Intention to increase use of public transportation as a function of political orientation and message

An ANOVA of the belief that communities and the government should make public transportation a priority revealed a significant main effect of political orientation, $F(1,135)=$ 5.21, $p=0.024, \eta p^{2}=0.037$. As expected, liberals $(M=1.79)$ were more apt to believe that public transportation should be a priority than participants who were relatively conservative $(M=$ 2.20). The political orientation by message interaction was not significant, $F<1$. Planned contrasts revealed that conservatives were not more likely to convey the belief that public transportation should be made a priority after meta-arguments $(M=1.94, S D=0.94)$ or conventional arguments $(M=2.04, S D=0.84)$, as opposed to the recycling control message ( $M$ $=2.28$. $S D=0.74$ ), were presented (meta-arguments vs. recycling control: $t(135)=1.46, p=$ $0.147, d=0.60$; conventional arguments vs. recycling control: $t<1)$. Liberals similarly were not more likely to convey that public transportation should be prioritized after meta-arguments $(M=$ $1.82, S D=0.55)$ or conventional arguments $(M=1.71 S D=0.75)$, as opposed to arguments for recycling $(M=1.86, S D=0.73)$, were communicated (both $t<1)$.

Finally, an ANOVA of participants' intentions to rely less on cars did not reveal a main effect of political orientation, $F(1,135)=1.65, p=0.202$, $\eta p^{2}=0.012$; liberals $(M=2.75$, $S D=1.09)$ did not convey different intentions from conservatives $(M=3.01, S D=1.00)$. The political orientation by message interaction was not significant, $F<1$. Planned contrasts revealed that conservatives did not express stronger intentions to diminish reliance on cars after metaarguments $(M=2.78, S D=0.81)$ or conventional arguments $(M=3.12, S D=1.13)$, as opposed to the recycling control message $(M=3.08, S D=1.00)$, were presented (both $t<1)$. Liberals similarly did not express different intentions to diminish reliance on cars after meta-arguments 
$(M=2.68, S D=1.12)$ or conventional arguments $(M=2.75, S D=1.03)$, as opposed to arguments for recycling $(M=2.86, S D=1.15)$, were communicated (both $t<1)$.

\subsection{THE IMPACT OF ENVIRONMENTAL ORIENTATION ON PERSUASION}

Analyses were conducted to examine whether the effects of the different types of communications on transportation attitudes and intentions depended on environmental attitudes. Participants were dichotomized as being pro-environment (an average response of 4 or higher to the questions on environmental attitudes) or not pro-environment (an average response less than 4). There were 83 pro-environment participants and 58 participants who were not proenvironment in the sample.

The mean evaluations of public transportation as a function of environmental attitudes and message type are presented in Figure 3.4. A 2 x 3 between-subjects ANOVA revealed a significant main effect of environmental orientation, $F(1,135)=19.40, p<0.001, \eta p^{2}=0.126$. Not surprisingly, pro-environment participants $(M=2.47, S D=0.87)$ evaluated public transportation much more favorably than participants who were not pro-environment $(M=1.69$, $S D=1.01)$. The environmental orientation by message interaction was not significant, $F(2,135)$ $=1.58, p=0.21, \eta p^{2}=0.023$. Planned contrasts revealed that participants who were not proenvironment tended to evaluate public transportation more favorably after meta-arguments were presented than after the recycling control message was presented, $t(135)=1.83, p=0.069, d=$ 0.64. The evaluations of people in the recycling control and conventional arguments conditions did not differ, $t<1$. Pro-environment participants in the conventional and meta-arguments message conditions evaluated public transportation similarly to those in the recycling control condition (meta-argument vs. recycling control: $t(135)=1.17, p=0.244, d=0.36$; conventional vs. recycling control: $t(135)=1.02, p=0.310, d=0.32)$. 


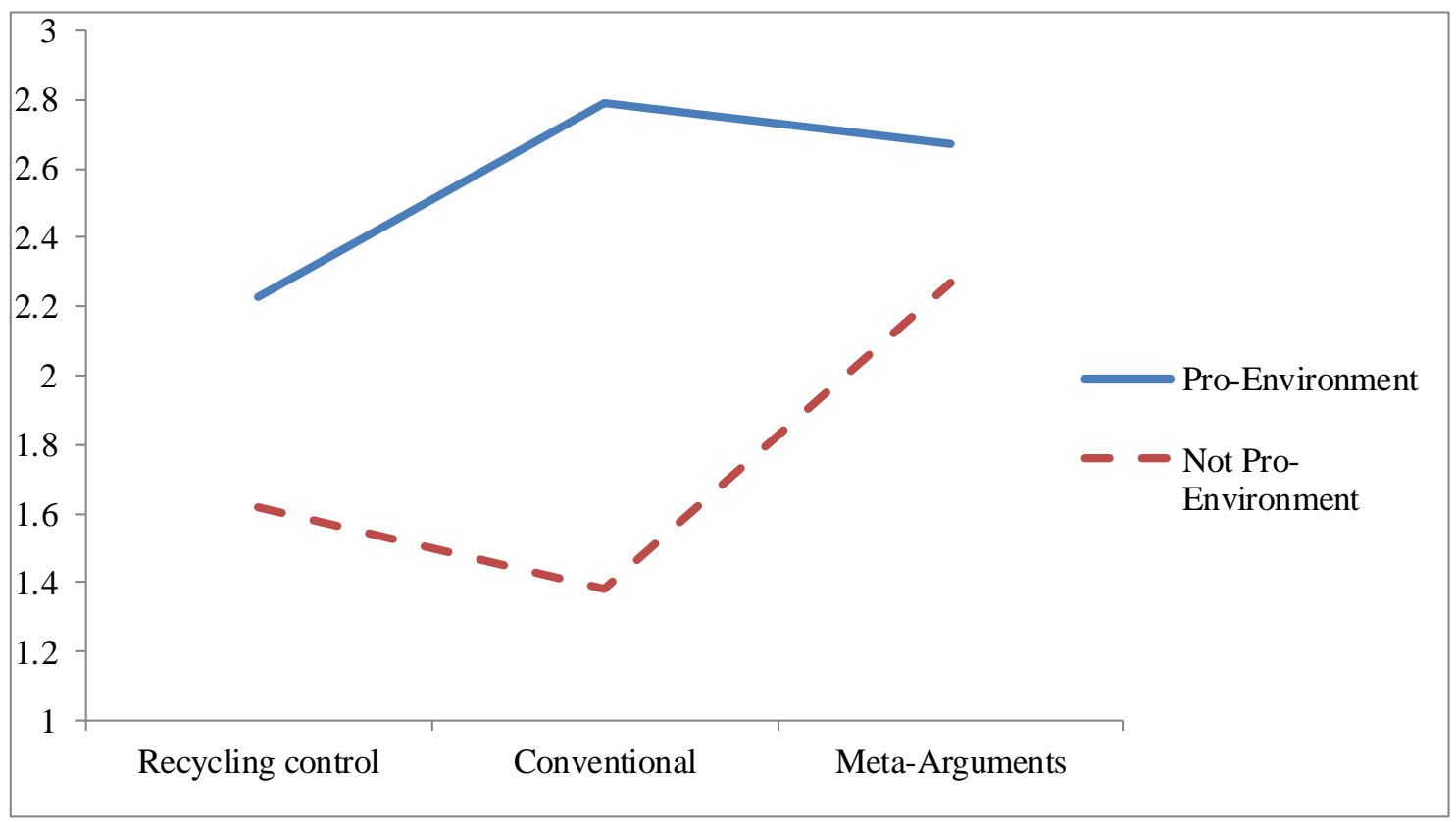

Figure 3.4: Attitude toward public transportation as a function of environmental orientation and message

An ANOVA of attitudes toward driving to work or school revealed a main effect of environmental attitudes, $F(1,135)=8.11, p=0.005, \eta p^{2}=0.057$. Not surprisingly, proenvironment participants $(M=0.45, S D=1.27)$ evaluated driving less favorably than participants who were not pro-environment $(M=1.17, S D=1.34)$. The environmental orientation by message interaction was not significant, $F<1$. Planned contrasts indicated that the attitudes toward driving of participants who were not pro-environment did not differ after metaarguments $(M=1.07, S D=1.28)$ or conventional arguments $(M=0.82, S D=1.47)$, as opposed to the recycling control message $(M=1.46, S D=1.27)$, were presented (meta-arguments vs. recycling control: $t<1$; conventional arguments vs. recycling control: $t(135)=1.58, p=0.117, d$ $=0.38$ ). Pro-environment participants similarly did not express more favorable attitudes toward driving after meta-arguments $(M=0.19, S D=1.14)$ or conventional arguments $(M=0.56, S D=$ 1.32 ), as opposed to arguments for recycling $(M=0.65, S D=1.39)$, were communicated (metaarguments vs. recycling control: $t(135)=1.24, p=0.217, d=0.27$; conventional arguments vs. recycling control: $t<1$ ).

Figure 3.5 presents the intention to increase use of public transportation as a function of environmental attitudes and the presented message. An ANOVA revealed a main effect of environmental orientation, $F(1,135)=30.60, p<0.001, \eta p^{2}=0.185$, as pro-environment participants $(M=2.10, S D=0.76)$ conveyed much stronger intentions to use public transportation than participants who were not pro-environment $(M=3.00, S D=1.01)$. The environmental orientation by message interaction was not significant, $F(2,135)=1.49, p=0.229$, 
$\eta p^{2}=0.022$. However, planned contrasts revealed that participants who were not proenvironment conveyed much stronger intentions to use public transportation after metaarguments were presented than after the recycling control message was presented, $t(135)=2.60$, $p=0.01, d=0.98$. The intentions of people in the recycling control and conventional arguments conditions did not differ, $t<1$. Pro-environment participants in the conventional argument and meta-argument conditions did not differ in their intentions to use sustainable transportation from participants in the recycling control condition (both $t<1$ ).

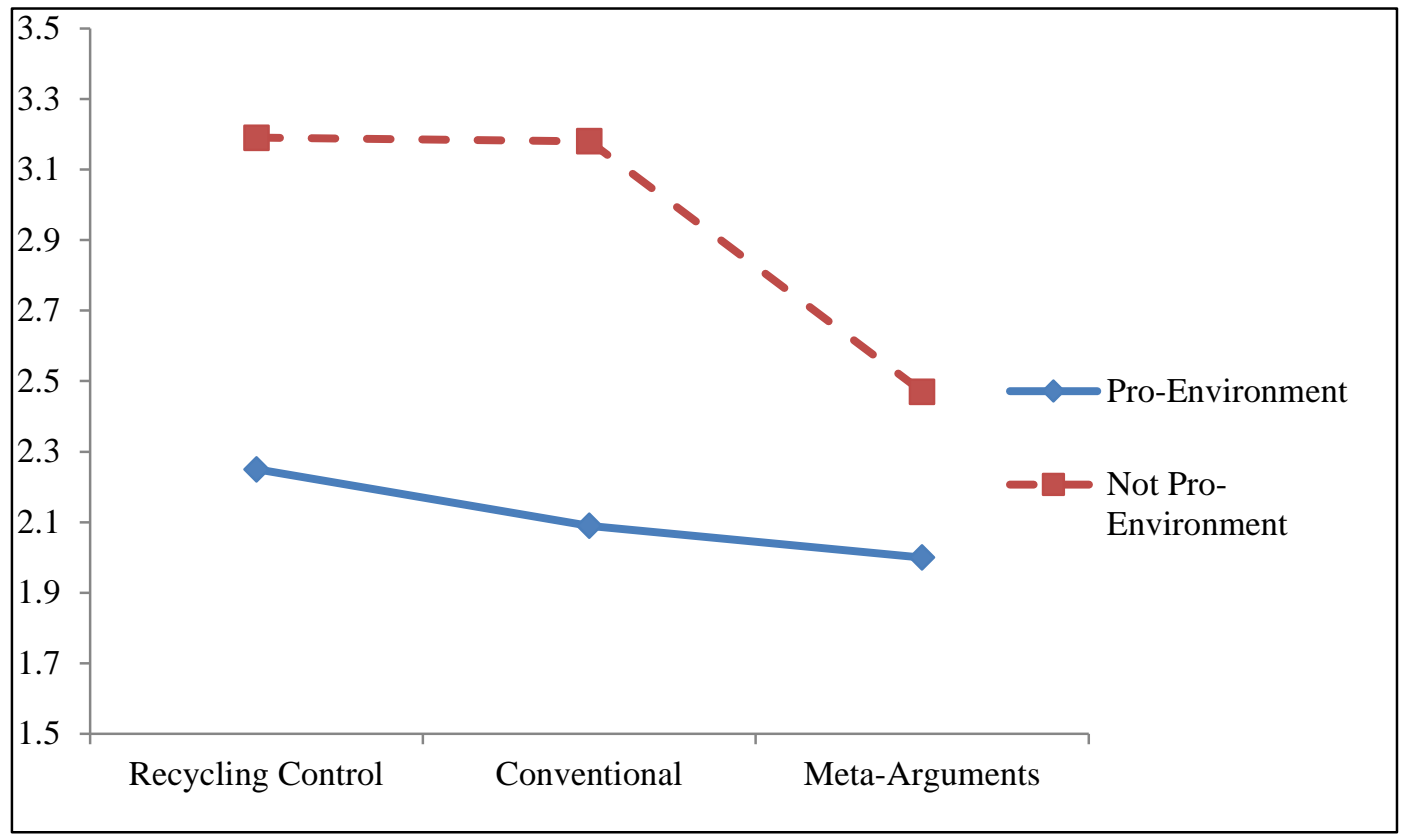

Figure 3.5: Intention to increase use of public transportation as a function of environmental attitudes and message

An ANOVA of the belief that communities and the government should make public transportation a priority revealed a main effect of environmental orientation, $F(1,135)=23.62, p$ $<0.001, \eta p^{2}=0.149$. Not surprisingly, pro-environment participants $(M=1.69, S D=0.62)$ were more likely to advocate prioritizing public transportation than participants who were not proenvironment $(M=2.31, S D=0.80)$. The environmental orientation by message interaction was not significant, $F<1$. Planned contrasts revealed that participants who were not proenvironment were not more likely to convey the belief that public transportation should be made a priority after meta-arguments $(M=2.20, S D=0.86)$ and conventional arguments $(M=2.35$, $S D=0.75)$ as opposed to the recycling control message $(M=2.35, S D=0.86)$ were presented (both $t<1$ ). Pro-environment participants similarly were not more likely to convey the belief that public transportation should be prioritized after meta-arguments $(M=1.71, S D=0.59)$ or conventional arguments $(M=1.63, S D=0.66)$ as opposed to arguments for recycling $(M=1.75$, $S D=0.64$ ) were communicated (both $t<1$ ). 
Finally, an ANOVA of participants' intentions to rely less on cars revealed a main effect of environmental attitudes, $F(1,135)=19.00, p<0.001, \eta p^{2}=0.123$, as pro-environment participants $(M=2.57, S D=0.90)$ conveyed much stronger intentions to diminish car usage than participants who were not pro-environment $(M=3.33, S D=1.10)$. The environmental attitudes by message interaction was not significant, $F<1$. Planned contrasts revealed that participants who were not pro-environment did not express stronger intentions to diminish reliance on cars after meta-arguments $(M=3.13, S D=1.25)$ or conventional arguments $(M=3.59, S D=1.23)$ as opposed to the recycling control message $(M=3.27, S D=0.92)$ were presented (both $t<1)$. Proenvironment participants similarly did not express stronger intentions to diminish reliance on cars after meta-arguments $(M=2.52, S D=0.81)$ or conventional arguments $(M=2.59, S D=$ $0.84)$ as opposed to arguments for recycling $(M=2.60, S D=1.14)$ were communicated (both $t<$ 1). 


\subsection{DISCUSSION AND CONCLUSIONS}

The presentation of meta-arguments in our experiment tended to contribute to more-favorable evaluations of public transportation and stronger intentions to use public transit. This suggests that communicating the benefits of holding more-positive attitudes toward buses and railways, and less-favorable attitudes toward driving, may be an alternative and effective approach for changing transportation behavior. Thus, the study may provide educators, environmentalists, and policymakers a new set of persuasive tools for changing negative attitudes toward public transportation, and increasing the use of buses and other forms of mass transit.

The study also contributes to theory on attitude change by demonstrating the persuasiveness of meta-arguments. A sizable body of research has investigated the role of attitude functions in attitude change (Maio \& Olsen, 2000; Sanbonmatsu et al., 2007). Studies have shown, for example, that the efficacy of communications depends, in part, on the functional match between the communicated arguments and the motivations of message recipients (DeBono, 1987; Petty \& Wegener, 1998). However, nearly all of this research has focused on arguments about the functions of attitude objects, rather than meta-arguments about the functions and benefits of particular attitudes. Our findings add to the attitudes literature by demonstrating the impact of meta-arguments about the functional value of an attitudinal position on persuasion.

Surprisingly, the conventional message had little impact on evaluations of public transportation, the intention to use public transportation, and the intention to rely less on cars in our experiment. We speculate that most college undergraduates are familiar with the conventional arguments presented for diminished driving and increased use of public transportation. For example, most students are probably aware that riding the bus is less expensive than maintaining and operating an automobile, and that increased mass transit use diminishes air pollution. Indeed, participants reported a high level of familiarity with the conventional arguments $(M=4.12$ on a five-point scale) and significantly less familiarity with the meta-arguments $(M=3.46), t(93)=2.90, p=$ $0.005, d=0.53$. As a consequence, the conventional message may have had little effect on changing the transportation attitudes and intentions of our participants. This is not to downplay the importance of disseminating conventional arguments for more sustainable transportation through public service messages. The findings simply illustrate that there are significant facets of the population that are unlikely to be moved by these communications. Conventional arguments would presumably be more likely to influence a younger audience that has not been previously exposed to this information.

A related explanation for the limited impact of the conventional arguments is that many participants came into the experiment with favorable attitudes toward mass transit. In particular, participants who were liberal and pro-environment tended to have a positive preexisting orientation. The mean evaluation of public transportation of pro-environment participants ( $\mathrm{M}=$ 2.25) and liberal participants $(\mathrm{M}=2.29)$ in the recycling control condition approached the ceiling of +3 on a 7 point scale. Thus, their attitudes were not likely to be strongly affected by any message favoring mass transit. The participants whose attitudes had room to move in a positive direction were those who were more politically conservative and not pro-environment. However, these participants were not persuaded by the conventional appeals for public transportation. 
Again, these arguments may have been familiar to them. Additionally, the functions of public transportation communicated by the conventional message may not have matched their motivational aims. Instead, participants who were politically conservative and not environmentally oriented were influenced by the presentation of the meta-arguments conveying utilitarian, identity, and social-adjustive benefits of holding more-favorable public transportation attitudes. These findings indicate that the relative efficacy of conventional and meta-arguments for sustainable transportation depends on the message recipient. Educators and policymakers may need to tailor their arguments for their audiences to maximize the impact of their communications.

Actual data on the benefits and costs of positive attitudes toward sustainable transportation were not easy to track down. We were unable to find statistics about the consequences of holding particular attitudes toward public transit and reliance on automobiles in any scientific journals. Rather, we had to scour reports by governmental agencies and consulting firms for this information. In some instances, we had to draw inferences about the upside of holding positive transportation attitudes from reports (Davis, Dutzik, and Baxandall, 2012; Greenwald, 2010). In the future, it might useful to systematically gather information about the costs and benefits of particular attitudinal positions so that more accurate, and perhaps more convincing, metaarguments can be devised to persuade the public.

Our research and findings are in line with the U.S. DOT strategic plan to transform our transportation system into one that burns less oil and emits less carbon. The study investigated kinds of communications that can help persuade people to drive less, and walk, bicycle, and use mass transit more. In addition, the study explored which persuasive arguments are likely to be most effective with different user groups. As such, it provides new tools for educational programs and communications aimed at changing people's transportation attitudes and behavior. Thus, the research was in keeping with the U.S. DOT goal to make our communities more livable by increasing the sustainability of transportation behavior. 


\subsection{REFERENCES}

B. Davis, T. Dutzik, and P. Baxandall. "Transportation and the new generation: Why young people are driving less and what it means for transportation policy.” Frontier Group and U.S. PIRG Education Fund, Washington DC, 2012.

K. G. DeBono. "Investigating the social adjustive and value-expressive functions of attitudes: Implications for persuasion processes.” Journal of Personality and Social Psychology 52 (1987): 279-287.

M. Greenwald. "Deloitte Report: Sustainability in business today: A cross-industry view." https://sustainableink.org/2010/08/09/deloitte-report-sustainability-in-business-today-a-crossindustry-view/ (2010)

Y. Heath and R. Gifford. "Extending the theory of planned behaviour: predicting the use of public transportation.” Journal of Applied Social Psychology 32 (2002): 2154-2185.

K. H. Karash, M. A. Coogan, T. Adler, C. Cluett, S. A. Shaheen, I. Ajzen, and M. Simon. "TCRP Report 123 - Understanding How Individuals Make Travel and Location Decisions: Implications for Public Transportation.” TRB, National Research Council, Washington DC, 2008.

D. Katz. "The functional approach to the study of attitudes." Public Opinion Quarterly 24 (1960): 163-204.

G. R. Maio and J. M. Olson. Why we evaluate: Functions of attitudes. Mahwah, NJ: Lawrence Erlbaum, 2000.

R. E. Petty and J. T. Cacioppo. Attitudes and persuasion: Classic and contemporary approaches. Dubuque, IA: William C. Brown Company Publishers, 1981.

R. E. Petty and D. T. Wegener. Matching versus mismatching attitude functions: Implications for scrutiny of persuasive messages.” Personality and Social Psychology Bulletin 24 (1998): 227240.

M. Rhindress, F. Lynch, S. Bregman, R. E. Reichman, N. J. Coopersmith, and J. A. Dunning. "TCRP Report 122: Understanding How to Motivate Communities to Support and Ride Public Transportation.” TRB, National Research Council, Washington DC, 2008.

D. M. Sanbonmatsu, S. S. Posavac, S. Vanous, S., E. A. Ho, and R. H. Fazio. “The deautomatization of accessible attitudes.” Journal of Experimental Social Psychology 43 (2007): 365-378.

V. Seyranian, G. M. Sinatra, and M. S. Polikoff. (2015). "Comparing communication strategies for reducing residential water consumption.” Journal of Environmental Psychology 41 (2015): 81-90. 
L. Steg and I. Sievers. "Cultural theory and individual perceptions of environmental risks." Environment and Behavior 32 (2000): 250-269.

C. Wan, G. Q. Shen, and S. Choi. "Experiential and instrumental attitudes: Interaction effect of attitude and subjective norm on recycling intention.” Journal of Environmental Psychology 50 (2017): 69-79. 
Transportation Research and Education Center

Portland State University

1900 S.W. Fourth Ave., Suite 175

Portland, OR 97201 